1 Variability in anuran advertisement call: A multi-level study with 15 species of monkey tree frogs (Anura: Phyllomedusidae)

David L. Röhr*, Felipe Camurugi, Gustavo B. Paterno, Marcelo Gehara, Flora A. Juncá,

5 D.L. Röhr Departamento de Ecologia, Universidade Federal do Rio Grande do Norte, Lagoa Nova,

6 59072-970, Natal, RN, Brazil, davidlucasr@yahoo.com.br

7 F. Camurugi Programa de Pós-Graduação em Ciências Biológicas (Zoologia), Departamento de

8 Sistemática e Ecologia, Centro de Ciências Exatas e da Natureza, Universidade Federal da Paraíba,

9 João Pessoa, 58059-900, PB, Brazil, camurugif@gmail.com

10 G.B. Paterno Departamento de Ecologia, Universidade Federal do Rio Grande do Norte, Lagoa Nova,

11 59072-970, Natal, RN, Brazil, paternogbc@gmail.com

12 M. Gehara Rutgers University-Newark, Department of Biological Sciences, 195 University Ave,

13 Newark, NJ 07102, USA, marcelo.gehara@gmail.com

14 F.A. Juncá Departamento de Ciências Biológicas, Universidade Estadual de Feira de Santana, BR

15 116, Km 03, Campus Universitário, 44031-460, Feira de Santana, BA, Brazil, florajunc@gmail.com

16 G.F.R. Álvares Laboratório de Fauna e Unidades de Conservação, Departamento de Engenharia

17 Florestal, Universidade de Brasília, 70.910-900, Brasília - DF, Brazil, aguilherme@hotmail.com

18 R.A. Brandão Laboratório de Fauna e Unidades de Conservação, Departamento de Engenharia

19 Florestal, Universidade de Brasília, 70.910-900, Brasília - DF, Brazil, reuberbrandao@gmail.com

20 A.A. Garda Departamento de Botânica e Zoologia, Universidade Federal do Rio Grande do Norte,

21 Campus Universitário, Lagoa Nova, 59072-970, Natal, RN, Brazil, pseudis@gmail.com

22 Corresponding author: Felipe Camurugi (camurugif@gmail.com)

23 *Present Address: Faculdade Pitágoras de Medicina de Eunápolis, Centauro, 45821-170, Eunápolis,

24 BA, Brazil 


\section{Variability in anuran advertisement call: A multi-level study with 15 species of monkey tree frogs (Anura: Phyllomedusidae)}

\section{Abstract}

30 Understanding the variability of acoustic signals is a first important step for the

31 comprehension of the evolutionary processes that led to current diversity. Herein, we evaluate

32 the variability of the advertisement call of the phyllomedusid species from the genera

33 Phyllomedusa and Pithecopus at different levels: intra-individual, intra-population, inter-

34 population, intra-species, and inter-specific. An analysis of coefficients of variation showed a

35 continuum of variability between the acoustic parameters analyzed, from static to highly

36 dynamic. Most of the variation was attributed to the inter-specific level while call parameters

37 at the intra-individual level varied the least. However, each parameter behaved differently

38 with call interval being the most variable across all levels. Most temporal acoustic parameters

39 were affected by environmental temperature while pulse rate and dominant frequency were

40 strongly influenced by body size. Only pulse rate was correlated to the geographic distance

41 between populations, while all parameters presented a significant phylogenetic signal. Based

42 on these results, we discuss the possible importance of different evolutionary forces and the

43 usage of vocalizations for taxonomic purposes.

44 Key words: acoustic communication, evolution, Pithecopus, Phyllomedusa, phylogenetic

45 signal, trait diversification, variation 


\section{Introduction}

47 Understanding variability is fundamental for the comprehension of evolution

48 (Hallgrimsson and Hall 2011). Darwin's observations on phenotypic variation were the basis

49 for the development of the concept of natural selection (Darwin 1859), and intra and inter-

50 specific variation were central for the modern evolutionary synthesis (Mayr 1966; Wright

51 1984). Acoustic signals are important for a large proportion of current fauna, and for most

52 groups it has a predominantly reproductive function (Bradbury and Vehrencamp 1998). There

53 is evidence that acoustic communication may not have increased the diversification rates of

54 terrestrial vertebrates at a macro evolutionary scale (Chen and Wiens 2020). However,

55 because these signals are involved in conspecific recognition, they may have a key role in

56 speciation of highly vocal groups, such as birds and frogs, and their importance as an

57 evolutionary force has been the focus of many studies (Wilkins et al. 2013).

Acoustic signals are the predominant form of communication for the vast majority of

59 anuran species. Although many species present more than one type of call, the advertisement

60 call emitted by males with the main function of attracting females can be considered the most

61 important acoustic signal for this clade (Wells 1977). Since the beginning of bioacoustic

62 studies on anurans, authors report that each species has a distinct advertisement call (Blair

63 1958, 1964; Duellman and Pyles 1983). Furthermore, it has been shown that females prefer

64 conspecific advertisement calls, even when considering sister taxa with relatively similar calls

65 (Gerhardt 1974; Backwell and Jennions 1993). Thus, this vocalization is considered an

66 important prezygotic reproductive barrier (Gerhardt and Huber 2002) and has been used as an

67 important taxonomic tool, helping overcome the lack of useful external morphological traits in

68 frogs (Padial and De la Riva 2009; Köhler et al. 2017).

69 The anuran advertisement call is considered stereotyped, especially in comparison to

70 other vertebrates such as birds and mammals. Still, there is considerable amount of intra- 
71 specific variation at the individual level (Howard and Young 1998), at the population level

72 (Sullivan 1982), and among populations of the same species (Sullivan 1989). Although

73 several studies clearly demonstrate this variation in each level separately, few studies have

74 quantified how different acoustic parameters vary across multiple levels (within and between

75 individuals, populations and species) (Castellano et al. 2002; Bee et al. 2010). Different

76 acoustic parameters from the same call are semi-independent and might encode distinct

77 messages, thus evolving under differing selective pressures (Gerhardt and Huber 2002; Ryan

78 and Kime 2003). Therefore, a broad comprehension of variability at different levels enables

79 the proposition of various hypotheses about the evolutionary mechanisms that led to the

80 present acoustic diversity.

81 In general, variation in acoustic signals can be related to pleiotropic effects (Podos

82 2001), stochastic processes (Goicoechea et al. 2010), natural selection (Ryan et al. 1990; Röhr

83 et al. in press), and sexual selection (Gerhardt 2005). For anurans, pleiotropic effects of

84 morphology and physiology are exemplified by the well-known influence of body size and

85 temperature on acoustic parameters. The size of the vocal apparatus usually affects spectral

86 parameters, while temperature often influences temporal characteristics of the calls (Gerhardt

87 1994). Such relationships can affect the variability of different acoustic parameters at different

88 levels. For example, acoustic parameters that are more dependent on temperature should vary

89 more, especially intra-individually and in a shorter time scale. At the same time, parameters

90 that are highly dependent on morphology should be more stereotyped, with most of the

91 variation occurring at levels above individuals or ontogenetically. Therefore, it is important to

92 carefully consider the influence of temperature and body size in any bioacoustic study.

93 Stochastic processes also affect the evolution and variability of acoustic signals. For

94 anurans, these effects are tested by evaluating the geographic variation of acoustic parameters

95 (Pröhl et al. 2007) or the effect of phylogeny on inter-specific variation (Goicoechea et al. 
96 2010). While some acoustic parameters vary mostly in response to stochastic processes, others

97 are not correlated with phylogeny or biogeography, possibly because they are under strong

98 selective forces (Erdtmann and Amézquita 2009). These different evolutionary pathways

99 should also influence the amount of variation detected at different levels.

100 Selection may affect the variability of acoustic parameters in different ways (Wilkins

101 et al. 2013). For example, acoustic parameters important for conspecific recognition are under

102 selective pressure not to overlap with calls from sympatric species, possibly leading to more

103 stereotypy and hence reducing the likelihood of hybridization (Lemmon 2009). Beyond this,

104 in diverse acoustic communities, calls might also be more stereotyped in order to use silent

105 windows and reduce masking interference (Chek et al. 2003; Bee 2008). At the same time, a

106 higher stereotypy might be expected in habitats with dense vegetation coverage, because the

107 acoustic propagation scenario is more stable compared to open areas, which are more

108 susceptible to wind and temperature shifts (Wiley and Richards 1978; Ey and Fischer 2009).

109 Nevertheless, most studies on the variability of anuran advertisement call have focused

110 on sexual selection (Gerhardt and Huber 2002). One key measurement of acoustic variation in

111 frogs is the individual coefficient of variation. Based on this measure, extensive literature has

112 shown that variability of different acoustic parameters follows a continuum from static to

113 dynamic (Gerhardt 1991; Castellano et al. 2002; Bee et al. 2010). Static parameters should be

114 under stabilizing or weakly directional sexual selection (Gerhardt 1991; Gerhardt and Huber

115 2002). Indeed, most studies confirm that females tend to prefer advertisement calls with

116 values close to the species/population mean for such acoustic parameters (Castellano and

117 Giacoma 1998; Rosso and Castellano 2006), and these parameters should be important for

118 specific recognition and are more reliable taxonomic tools (Köhler et al. 2017). In contrast,

119 acoustic parameters with high individual variability should be under directional selection due

120 to female preferences for calls with more extreme values (Castellano and Giacoma 1998; 
121 Bosch and Márquez 2005) which indicate male's quality or facilitate localization (Gerhardt

122 1994; Gerhardt and Huber 2002).

123 Herein, we evaluate the variability of different acoustic parameters of the

124 advertisement call of 15 tree frog species of the family Phyllomedusidae at different levels:

125 intra-individual, intra-population, inter-population, intra-specific, and inter-specific. We also

126 estimated what percentage of the total variation detected can be explained by each level.

127 Furthermore, we tested: 1) the effect of environmental temperature and body size on the

128 acoustic parameters, 2) if they present significant phylogenetic signal and 3) if they are

129 correlated to geographic distance between populations.

\section{Material and Methods}

132 Study organisms and data collection

133 The family Phyllomedusidae, commonly known as monkey tree frogs, currently

134 harbors 66 species distributed in the Neotropics (Duellman et al. 2016; Frost 2018). In Brazil,

135 the genera Phyllomedusa and Pithecopus are widely distributed, virtually found in all biomes.

136 The former is composed of 16 large species, while the latter comprises 11 smaller species. We

137 recorded the advertisement call of 15 species from both genera (Figure 1) across a large

138 spatial scale, encompassing 31 localities and 13 states throughout Brazil (Figure 2; Table S1

139 in Supplementary Material): Phyllomedusa bahiana Lutz, 1925, P. burmeisteri Boulenger,

140 1882, P. camba De la Riva, 1999, P. distincta Lutz, 1950, P. iheringii Boulenger, 1885, P.

141 tetraploidea Pombal and Haddad, 1992, and P. vailantii Boulenger, 1882; Pithecopus ayeaye

142 Lutz, 1966, P. azureus (Cope, 1862), P. centralis (Bokermann, 1965), P. hypocondrialis

143 (Daudin, 1800), P. megacephalus (Miranda-Ribeiro, 1926), P. nordestinus (Caramaschi,

144 2006), P. oreades (Brandão, 2002), and P. rohdei (Mertens, 1926). Although P. tetraploidea

145 and P. distincta can hybridize along a geographic contact zone (Haddad et al. 1994), our 
146 sampling points comprised allopatric populations, therefore obviating the problem of hybrid

147 specimens (see Figure 2 for the spatial distribution of samples).

148 We used a Marantz PMD 660 digital recorder with a sampling rate of $48 \mathrm{kHz}$ and 16-

149 bit resolution, connected to a Sennheiser ME66 directional microphone for most recordings.

150 After recording most individuals, we measured the environmental temperature and snout-vent

151 length (see Table S1 in Supplementary Material for data on each recording: species, locality,

152 coordinates, temperature, body size, and total number of calls analyzed). Acoustic parameters

153 were measured in Raven Pro 1.4 and spectrograms produced as follows: FFT window width $=$

$154256 ;$ Frame $=100 ;$ Overlap $=50 \%$.

155 We analyzed a total of six acoustic parameters for all calls recorded, which are

156 comparable at all levels, even between different species of these genera. We used the

157 terminology for acoustic parameters after Köhler et al. (2017): peak of the dominant

158 frequency (DF), call duration (CD), total number of pulses in the call (number of pulses - NP),

159 average pulse duration considering all pulses from the call (pulse duration - PD), pulse rate

160 (PR) as the ratio between NP and CD, and interval between calls (inter-call interval - CI) (see

161 Figure 3 for details). Calls of Phyllomedusa and Pithecopus are structured in pulses that may

162 be grouped into separate notes. Because calls of different species may or not present more

163 than one note, making it difficult to establish homology between notes, the number of notes

164 was not included in the analyses.

\section{Acoustic variation analyses}

166 To estimate the variability of acoustic parameters we calculated the coefficient of

167 variation $(\mathrm{CV})$, which is a standardized measure of dispersion calculated through the ratio of

168 the standard deviation to the mean, for all acoustic parameters at five different levels: 1) intra-

169 individual (different calls from a single individual), 2) intra-population (calls from different 
170 individuals from a single population), 3) inter-population (calls from individuals from

171 different populations), 4) intra-species (calls from different individuals from the same species,

172 independent from which population), and 5) inter-specific (calls from individuals from

173 different species).

174 A stratified hierarchical subsampling method was implemented to deal with the

175 unbalanced sample sizes across species (see Table S2 in Supplementary Material). We

176 repeatedly drew from our data pool five different calls that were used to calculate the $\mathrm{CV}$. We

177 ensured that calls were drawn from different entities forming the respective level of interest.

178 For instance, before drawing five calls at the intra-individual level, we drew a species, then a

179 population, then an individual, then five different calls. For the intra-population level, we first

180 drew a species, then a population, then five calls from different individuals and so on (see

181 Table 1 for a stepwise description of all steps used to obtain the calls used for each level). We

182 repeated each subsampling 1,000 times for each level to create five distributions of variation

183 for each acoustic parameter. For intra and inter-population levels, we only used data from

184 Pithecopus nordestinus due to the lack of sufficient population replicates for the other species.

185 Due to the low number of samples for P. burmeisteri and P. vaillanti, these species were only

186 included in the inter-specific variation level analysis. Additionally, we performed a hierarchical ANOVA to calculate the amount of

188 variation that can be attributed to each level. For this analysis we used only four levels in

189 order to access the variability repartition: call, individual, population, and species. To test the

190 influence of body size (BS) and environmental temperature on acoustic parameters, we

191 performed linear mixed models using species as random effect. In this analysis, we used the

192 mean value from all calls from each individual, with the acoustic parameters as response

193 variables and BS and temperature as predictors. To test the correlation between acoustic

194 parameters and geographic distance between different populations of $P$. nordestinus, we 
195 applied a Mantel test for each acoustic parameter. In the correlation matrix we included

196 geographical coordinates of each locality and the mean acoustic parameters for each

197 individual and population.

198

199

200

201

202

203

204 vary continuously from 0 , with $\mathrm{K}$-values equal to 1 suggesting that traits are under BM; when

205 larger than one, related species present trait values more similar than expected by BM; and

206 when it is smaller than one, relatives are less similar than expected (Blomberg et al. 2003).

207 For this analysis we used the phylogeny from Pyron and Wiens 2011. All analyses were done

208 on the R 3.1.2. environment using the following packages: lme4 (Bates et al. 2015); ape

209 (Paradis et al. 2019); picante (Kembel 2010); phytools (Revell 2012), and tidyverse (Wickham

\section{Sensitivity analysis}

212 To ensure that our results and the reported patterns were not an artefact of species with low

213 sampling, we repeated the coefficient of variation and hierarchical ANOVA analyses after

214 excluding data from species with less than 5 individuals and less than 30 different calls (Table

215 S2 in Supplementary Material): P. burmeisteri, P. vaillantii, P. megacephalus, and P. azureus.

216 Results from this sensitivity analysis remained substantively the same compared to the

217 analysis of the full dataset and, thus, we report the original result in the main text while results

218 from the sensitivity analysis are reported in the supplementary material (see Figures S2-3 in 


\section{Results}

221 We analyzed a total of 3,994 advertisement calls from 188 individuals of 15 different

222 species of phyllomedusids (Figure 1). Although we sampled calls from more than one locality

223 for various species, we only obtained enough samples from different populations for

224 Pithecopus nordestinus, for which we recorded various individuals from 14 populations from

225 different localities distributed throughout most of the species geographical distribution (Figure

226 2; Table S1 in Supplementary Material). The advertisement calls from all species recorded is

227 relatively simple, being composed of several similar pulses that can be grouped in different

228 notes (see Table 2 for the mean values of the acoustic parameters for the species recorded and

229 Figure S1 in Supplementary Material for spectrograms of one call from each species).

230 The multiple-level analyses of variability using CV showed that all acoustic

231 parameters presented the lowest variation intra-individually, but the intensity of this trend

232 varied between parameters. Dominant frequency, pulse duration, and pulse rate are the most

233 static parameters, especially intra-individually. Number of pulses and call duration present

234 intermediate values, while call interval is highly dynamic and shows less difference between

235 the intra-specific levels and the inter-specific level (Figure 4).

236 Call parameters also vary considerably below the interspecific level. In general, the

237 variability is smallest at the intra-individual level for all parameters and a tendency for the

238 intra-population level to show less variability than the inter-population, with the intra-specific

239 intermediate. Furthermore, the three most static parameters (dominant frequency, pulse

240 duration, and pulse rate) show the largest difference inter-specifically compared to other

241 levels (Figure 4).

242 The ANOVA confirmed the results from our multi-level CV evaluation, where most of 
243 the advertisement call variability is explained by inter-specific differences. However, this

244 trend also varies a lot between parameters. There is a clear tendency for static acoustic

245 parameters to have a larger percentage of their variability credited to the inter-specific level,

246 with intermediate parameters having a little less of their variability explained by this level

247 (however more than 75\%) and the dynamic parameter less than 50\%. Below the inter-specific

248 level, pulse rate had a considerable part of its variation attributed to the population level

249 (Figure 5).

The linear mixed models showed that most of the acoustic parameters are significantly

251 affected by body size and/or environmental temperature. While temperature affected mostly

252 temporal acoustic parameters (CD, PN and PR), individuals body size affected the spectral

253 parameter (DF) and PR, but most of variation was attributed to species identity (Table 3).

254 Only pulse rate and call duration were significantly correlated to the geographical distance

255 between individuals of $P$. nordestinus (Table 4). Conversely, all acoustic parameters tested

256 presented a significant phylogenetic signal, with $K$ values $<1$ (Table 5).

\section{Discussion}

258 Acoustic parameters show a continuous variability from individuals to species, but

259 with varying degrees of differentiation according to each parameter. These results corroborate

260 most studies on acoustic variability of anuran advertisement calls (Castellano et al. 2002;

261 Reinhold 2009; Bee et al. 2010). We are unaware of others studies using, at the same time, so

262 many hierarchical levels in an evolutionary approach. Studying the variability of acoustic

263 parameters of anuran's advertisement calls in a multi-level approach has impact for both

264 taxonomy and evolutionary research, and even for studies which use automatic recording units

265 to monitor biodiversity. The parameters that presented the lowest CV were mainly those that

266 are considered important for frog specific recognition, especially dominant frequency and 
267 pulse rate (Gerhardt 1994). Tests on female preference demonstrate that they generally prefer

268 calls with medium values for those parameters, exerting a stabilizing sexual selection over the

269 population (Castellano and Giacoma 1998). Furthermore, studies on reproductive character

270 displacement show that when populations occur in sympatry with sister taxa with similar

271 advertisement calls these preferences are stronger, confirming the importance of these

272 parameters for specific recognition and as reproductive barrier, diminishing hybridization

273 (Lemmon 2009). However, for some frog species females prefer calls with slightly lower

274 dominant frequencies, exerting weak directional sexual selection, possibly choosing for larger

275 males (Ryan 1980; Poole and Murphy 2007).

276 Considering the more variable parameters, call duration and number of pulses

277 presented intermediate values of $\mathrm{CV}$, while call interval was highly dynamic. Although the

278 range of variation may vary according to species, this is a general tendency for parameter

279 variation in anurans (see review in Köhler et al. 2017). These acoustic parameters are

280 behaviorally controlled to some extent and are directly involved in the energetic expenditure

281 of call production (Gillooly and Ophir 2010; Ziegler et al. 2016). Accordingly, females

282 generally show directional preferences for these parameters (Sullivan 1992; Bosch and

283 Márquez 2005). These more extreme values from the population/species distribution could

284 indicate higher fitness males or just enhance probability of signal detection and facilitate

285 localization, and different sexual selection mechanisms might be involved (Ryan 1988;

286 Bruner et al. 2017).

287 As expected, the inter-specific level was the most variable and most of the

288 advertisement call variability for phyllomedusids is attributed to this level, while the lowest

289 CV was detected intra-individually, except for call interval, which has a high variability at all

290 levels (Figures 3 and 4). These results indicate that the advertisement call for these species

291 might be a reliable taxonomic tool (Köhler et al. 2017), yet, the influence of temperature and 
292 body size should always be taken into consideration. Even though environmental temperature

293 and body size significantly affected four from six acoustic parameters, species identity

294 explained most of the variation of these parameters.

295 Variability in levels that compare calls from different individuals of the same species

296 also changed as predicted. Parameters showed less variability at the intra-population level in

297 relation to inter-population, with intermediate values for intra-specific, probably because it

298 includes calls from individuals which may or not be from the same population. However,

299 variation between populations was small when compared to studies on other anurans (Snyder

300 and Jameson 1965; Hasegawa et al. 1999; Castellano et al. 2000; Kaefer et al. 2012). Inter-

301 population variation may be associated to stochastic processes and be directly related to gene

302 flow or selection (Smith et al. 2003; Bernal et al. 2005; Pröhl et al. 2007; Ohmer et al. 2009;

303 Kaefer and Lima 2012), which may act directly on call characteristics or through pleiotropic

304 effects (Ryan et al. 1990; Castellano et al. 1999). When selective pressures are weak, call

305 variation is expected to be correlated with geographical distance between populations or

306 associated to an important dispersal barrier (Pröhl et al. 2006; Maia et al. 2017). From the

307 acoustic parameters evaluated for P. nordestinus only pulse rate and call duration were related

308 to geographical distance between individuals, although there was no relationship at the

309 population level. Conversely, pulse rate had a higher percentage of its variation explained by

310 the population level when compared to the other static parameters. This low variability

311 between different populations and its absent correlation with geographical distance may be

312 related to conservative selective pressures acting upon all or most populations, to a large

313 amount of gene flow, or because of recent population expansions. Thus, studies on geographic

314 variation of anuran advertisement calls found contrasting results on the relationship between

315 call variation and geographic distances (Snyder and Jameson 1965; Hasegawa et al. 1999;

316 Castellano et al. 2000; Smith et al. 2003; Bernal et al. 2005; Pröhl et al. 2007; Ohmer et al. 
317 2009; Kaefer and Lima 2012; Kaefer et al. 2012).

318 Conversely, when considering the variation between calls from the different species

319 studied, all acoustic parameters presented a significant phylogenetic signal. Nevertheless,

320 parameters had K-values lower than one, suggesting that traits varied more than expected by

321 Brownian motion. Because behavioral traits are generally more labile (Blomberg et al. 2003),

322 and call parameters can be under different selective pressures, it's possible to have directional

323 selection even with a phylogenetic signal in advertisement call of phyllomedusids. These

324 results corroborate most studies on phylogenetic signals for anurans (Wollenberg et al. 2007;

325 Erdtmann and Amézquita 2009; Goicoechea et al. 2010; Gingras et al. 2013). Although the

326 anuran advertisement call traditionally is seen as a rapidly evolving trait and under strong

327 selective forces, especially sexual selection (Gerhardt 1994), studies have found surprisingly

328 strong phylogenetic signals for most acoustic parameters tested, calling attention to the

329 importance of stochastic processes, such as genetic drift, in the evolution of these

330 vocalizations (Cocroft and Ryan 1995; Wollenberg et al. 2007; Erdtmann and Amézquita

331 2009; Goicoechea et al. 2010).

332 Our results confirm that the advertisement call of the species studied from the family

333 Phyllomedusidae may be used as a reliable taxonomic tool, because all acoustic parameters

334 analyzed, except call interval, presented a much higher inter-specific variation in comparison

335 to all intra-specific levels. However, considering the variation detected for the different intra-

336 specific levels, it is important to have adequate replicates from different localities.

337 Furthermore, it is recommended to consider temperature and body size, because most of the

338 acoustic parameters were influenced by one or another variable. CV at different levels shows

339 that, between the analyzed acoustic parameters, dominant frequency and pulse rate are the

340 most reliable parameters for taxonomy. The variation is a central component of evolution.

341 Thus, studies that take into account how and how much traits vary across multiple levels can 
342 help us to understand which factors (e.g. genetic drift, sexual selection, environment, etc.) can

343 shape diversification of species.

\section{Acknowledgements}

345 AAG and FAJ thank CNPq for financial support (Universal \# 473503/2012-3 and

346 \#305704/2013-3, respectively). DLR also thanks Sisbiota Herpeto-Helmintos project for

347 financial support. GFRA and RAB thanks Fundação Grupo O Boticário for financial support

348 (Project \#0725_20062). For collecting permits Sisbio 32479. We thank Vinícius São Pedro,

349 Taís Costa and Rogério Bastos for providing recordings of some individuals and everybody

350 who helped during field work. We thank to Ricardo Marques (P. nordestinus, P. rohdei, P.

351 bahiana and P. burmeisteri), Leandro Alves (P. hypochondrialis and P. vaillantii), Diego J.

352 Santana (P. azureus, P. camba and P. distincta), Sarah Mângia (P. tetraploidea) and Márcio

353 Borges-Martins (P. iheringii), who kindly provided photos. AAG thanks CNPq for his

354 productivity research grant (\#310942/2018-7). This study was financed in part by the

355 Coordenação de Aperfeiçoamento de Pessoal de Nível Superior - Brasil (CAPES) - Finance

356 Code 001. This study has been performed according to the Declaration of Helsinki, approved

357 by the Universidade Federal do Rio Grande do Norte Animal Ethics Committee (no

358 024/2011) and procedures were approved by Brazilian Environment Ministry

359 (SISBIO/ICMBio no 32479-3, 07/03/2014).

360 Data availability

361 The raw data and the code used in the analyses are available online at

362 https://github.com/paternogbc/ms_variability_anuran_call

\section{References}


Backwell, P.R.Y., and Jennions, M.D. 1993. Mate choice in the Neotropical frog, Hyla ebraccata: Sexual selection, mate recognition and signal selection. Anim. Behav. 45(6): 1248-1250. doi:10.1006/anbe.1993.1150.

367 Bates, D., Maechler, M, Bolker, B, and Walker, S. 2015. Fitting linear mixed-effects models using lme4. J. of Stat. Softw. 67(1): 1-48. doi: 10.18637/jss.v067.i01.

369 Bee, M.A. 2008. Finding a mate at a cocktail party: Spatial release from masking improves acoustic mate recognition in grey treefrogs. Anim. Behav. 75(5): 1781-1791. doi:10.1016/j.anbehav.2007.10.032.

372 Bee, M.A., Cook, J.M., Love, E.K., O’Bryan, L.R., Pettitt, B.A., Schrode, K., and Vélez, A.

373 2010. Assessing acoustic signal variability and the potential for sexual selection and social recognition in boreal chorus frogs (Pseudacris maculata). Ethology 116(6): 564-

376 Bernal, X.E., Guarnizo, C., and Lüddecke, H. 2005. Geographic variation in advertisement call and genetic structure of Colostethus palmatus (Anura, Dendrobatidae) from the Colombian Andes. Herpetologica 61(4): 395-408. doi:10.1655/04-87.1.

Blair, W.F. 1958. Call structure and species groups in U. S. treefrogs (Hyla). Southwest. Nat. 3(1/4): 77. doi:10.2307/3669039.

381 Blair, W.F. 1964. Isolating mechanisms and interspecies interactions in anuran amphibians. Q. Rev. Biol. 39(4): 334-344. doi:10.1086/404324.

383 Blomberg, S.P., Garland, T., and Ives, A.R. 2003. Testing for phylogenetic signal in comparative data: Behavioral traits are more labile. Evolution 57(4): 717-745. doi:10.1111/j.0014-3820.2003.tb00285.x. 
390 Bradbury, J.W., and Vehrencamp, S.L. 1998. Principles of Animal Communication. Sinauer Associates, Sunderlan.

392 Bruner, J.P., Brusse, C., and Kalkman, D. 2017. Cost, expenditure and vulnerability. Biol. 393 Philos. 32(3): 357-375. Springer Netherlands. doi:10.1007/s10539-017-9563-5.

394 Castellano, S., Cuatto, B., Rinella, R., Rosso, A., and Giacoma, C. 2002. The advertisement 395 call of the European treefrogs (Hyla arborea): A multilevel study of variation. Ethology 108(1): 75-89. doi:10.1046/j.1439-0310.2002.00761.x.

397 Castellano, S., and Giacoma, C. 1998. Stabilizing and directional female choice for male calls 398 in the European green toad. Anim. Behav. 56: 275-287. doi:10.1006/anbe.1998.0784.

399 Castellano, S., Giacoma, C., and Dujsebayeva, T. 2000. Morphometric and advertisement call 400 geographic variation in polyploid green toads. Biol. J. Linn. Soc. 70(2): 341-360. doi:10.1006/bij1.1999.0391.

402 Castellano, S., Rosso, A., Doglio, S., and Giacoma, C. 1999. Body size and calling variation 403 in the green toad (Bufo viridis). J. Zool. 248(1): 83-90. doi:10.1111/j.1469404 7998.1999.tb01025.x.

405 Chek, A. a, Bogart, J.P., and Lougheed, S.C. 2003. Mating signal partioning in multi-species assemblages: a null model test using frogs. Ecol. Lett. 6: 235-247. doi:10.1046/j.1461-

408 Chen, Z., and Wiens, J.J. 2020. The origins of acoustic communication in vertebrates. Nat. 409 Commun. 11(1): 369. doi:10.1038/s41467-020-14356-3.

410 Cocroft, R., and Ryan, M. 1995. Patterns of advertisement call evolution in toads and chorus 411 frogs. Anim. Behav. 49(2): 283-303. doi:10.1006/anbe.1995.0043.

412 Darwin, C. 1859. On the Origin of Species by Means of Natural Selection, or the Preservation 413 of Favoured Races in the Struggle for Life. Murray, London. 
414 Duellman, W.E., Marion, A.B., and Hedges, S.B. 2016. Phylogenetics, classification, and

415 biogeography of the treefrogs (Amphibia: Anura: Arboranae). Zootaxa 4104(1): 1-109. 416 doi:10.11646/zootaxa.4104.1.1.

417 Duellman, W.E., and Pyles, R.A. 1983. Acoustic resource partitioning in anuran communities. $418 \quad$ Copeia 1983(3): 639-649. doi:10.2307/1444328.

419 Erdtmann, L., and Amézquita, A. 2009. Differential evolution of advertisement call traits in 420 dart-poison frogs (Anura: Dendrobatidae). Ethology 115(9): 801-811.

421 doi:10.1111/j.1439-0310.2009.01673.x.

422 Ey, E., and Fischer, J. 2009. The "acoustic adaptation hypothesis"- a review of the evidence

423 from birds, anurans and mammals. Bioacoustics 19: 21-48.

424 doi:10.1080/09524622.2009.9753613.

425 Frost, D.R. 2018. Amphibian species of the world: An online reference. Available at $426 \mathrm{http} / / /$ research.amnh.org/herpetology/amphibia/index.html. Available from 427 http://research.amnh.org/herpetology/amphibia/index.html [accessed 18 September $428 \quad 2018]$.

429 Gerhardt, H.C. 1974. Behavioural isolation of the tree frogs, Hyla cinerea and Hyla $430 \quad$ andersonii. Am. Midl. Nat. 91(2): 424-433. doi:10.2307/2424332.

431 Gerhardt, H.C. 1991. Female mate choice in treefrogs: Static and dynamic acoustic criteria. 432 Anim. Behav. 42(4): 615-635. doi:10.1016/S0003-3472(05)80245-3.

433 Gerhardt, H.C. 1994. The evolution of vocalization in frogs and toads. Annu. Rev. Ecol. Syst. 434 25(1): 293-324. doi:10.1146/annurev.es.25.110194.001453.

435 Gerhardt, H.C. 2005. Advertisement-call preferences in diploid-tetraploid treefrogs (Hyla 436 chrysoscelis and Hyla versicolor): Implications for mate choice and the evolution of 437 communication systems. Evolution 59(2): 395-408. doi:10.1111/j.0014$438 \quad$ 3820.2005.tb00998.x. 
439 Gerhardt, H.C., and Huber, F. 2002. Acoustic Communication in Insects and Anurans:

440 Common Problems and Diverse Solutions. University of Chicago Press, Chicago.

441 Gillooly, J.F., and Ophir, A.G. 2010. The energetic basis of acoustic communication. Proc. R.

442 Soc. B-Biological Sci. 277(1686): 1325-1331. doi:10.1098/rspb.2009.2134.

443 Gingras, B., Mohandesan, E., Boko, D., and Fitch, W.T. 2013. Phylogenetic signal in the 444 acoustic parameters of the advertisement calls of four clades of anurans. BMC Evol.

445 Biol. 13(1): 1. BMC Evolutionary Biology. doi:10.1186/1471-2148-13-134.

446 Goicoechea, N., De La Riva, I., and Padial, J.M. 2010. Recovering phylogenetic signal from 447 frog mating calls. Zool. Scr. 39(2): 141-154. doi:10.1111/j.1463-6409.2009.00413.x.

448 Haddad, C.F.B., Pombal Jr., J.P. and Batistic, R.F. 1994. Natural hybridization between 449 diploid and tetraploid species of leaf-frogs, genus Phyllomedusa (Amphibia). Journal of $450 \quad$ Herpetology 28(4): 425-430. doi:10.2307/1564953

451 Hallgrimsson, B., and Hall, B.K. 2011. Variation: a Central Concept in Biology. Elsevier $452 \quad$ Academic Press, Burlington, MA.

453 Hasegawa, Y., Ueda, H., and Sumida, M. 1999. Clinal geographic variation in the 454 advertisement call of the wrinkled frog, Rana rugosa. Herpetologica 55(3): 318-324.

455 Howard, R.D., and Young, J.R. 1998. Individual variation in male vocal traits and female 456 mating preferences in Bufo americanus. Anim. Behav. 55(5): 1165-1179. 457 doi:10.1006/anbe.1997.0683.

458 Kaefer, I.L., and Lima, A.P. 2012. Sexual signals of the Amazonian frog Allobates 459 paleovarzensis: Geographic variation and stereotypy of acoustic traits. Behaviour 149(1): $460 \quad 15-33$. doi:10.1163/156853912X623757.

461 Kaefer, I.L., Tsuji-Nishikido, B.M., and Lima, A.P. 2012. Beyond the river: Underlying 462 determinants of population acoustic signal variability in Amazonian direct-developing 463 Allobates (Anura: Dendrobatoidea). Acta Ethol. 15(2): 187-194. doi:10.1007/s10211- 
465 Kembel, S.W., Cowan, P.D., Helmus, M.R., Cornwell, W.K., Morlon, H., Ackerly, D.D., 466 Blomberg, S.P. and Webb, C.O., 2010. Picante: R tools for integrating phylogenies and 467 ecology. Bioinformatics, 26(11): 1463-1464. doi: 10.1093/bioinformatics/btq166.

468 Köhler, J., Jansen, M., Rodríguez, A., Kok, P.J.R., Toledo, L.F., Emmrich, M., Glaw, F., 469 Haddad, C.F.B., Rödel, M.O., and Vences, M. 2017. The use of bioacoustics in anuran 470 taxonomy: Theory, terminology, methods and recommendations for best practice. 471 Zootaxa 4251(1): 1-124. doi:10.11646/zootaxa.4251.1.1.

472 Lemmon, E.M. 2009. Diversification of conspecific signals in sympatry: Geographic overlap 473 drives multidimensional reproductive character displacement in frogs. Evolution 63: 1155-1170. doi:10.1111/j.1558-5646.2009.00650.x.

475 Maia, G.F., Lima, A.P., and Kaefer, I.L. 2017. Not just the river: Genes, shapes, and sounds 476 reveal population-structured diversification in the Amazonian frog Allobates tapajos 477 (Dendrobatoidea). Biol. J. Linn. Soc. 121(1): 95-108. doi:10.1093/biolinnean/blw017. 478 Mayr, E. 1966. Animal Species and Evolution. Belknap Press of Harvard University Press, $479 \quad$ Cambridge.

480 Ohmer, M.E., Robertson, J.M., and Zamudio, K.R. 2009. Discordance in body size, colour 481 pattern, and advertisement call across genetically distinct populations in a Neotropical 482 anuran (Dendropsophus ebraccatus). Biol. J. Linn. Soc. 97(2): 298-313. doi:10.1111/j.1095-8312.2009.01210.x.

484 Padial, J.M., and De la Riva, I. 2009. Integrative taxonomy reveals cryptic Amazonian species 485 of Pristimantis (Anura: Strabomantidae). Zool. J. Linn. Soc. 155(1): 97-122. doi:10.1111/j.1096-3642.2008.00424.x.

487 Paradis, E. and Schliep, K. 2019. ape 5.0: an environment for modern phylogenetics and 488 evolutionary analyses in R. Bioinformatics 35: 526-528. 
doi:10.1093/bioinformatics/bty633.

490 Podos, J. 2001. Correlated evolution of morphology and vocal signal structure in Darwin's 491 finches. Nature 409(6817): 185-188. doi:10.1038/35051570.

492 Poole, K.G., and Murphy, C.G. 2007. Preferences of female barking treefrogs, Hyla gratiosa, 493 for larger males: Univariate and composite tests. Anim. Behav. 73(3): 513-524. 494 doi:10.1016/j.anbehav.2006.09.008.

495 Pröhl, H., Hagemann, S., Karsch, J., and Höbel, G. 2007. Geographic variation in male sexual 496 signals in strawberry poison frogs (Dendrobates pumilio). Ethology 113(9): 825-837. doi:10.1111/j.1439-0310.2007.01396.x.

498 Pröhl, H., Koshy, R.A., Mueller, U., Rand, A.S., and Ryan, M.J. 2006. Geographic variation 499 of genetic and behavioral traits in northern and southern túngara frogs. Evolution 60(8): $500 \quad$ 1669. doi:10.1554/05-278.1.

501 Pyron, R.A., and Wiens, J.J. 2011. A large-scale phylogeny of Amphibia including over 2800 502 species, and a revised classification of extant frogs, salamanders, and caecilians. Mol. 503 Phylogenet. Evol. 61(2): 543-583. Elsevier Inc. doi:10.1016/j.ympev.2011.06.012.

504 Reinhold, K. 2009. Variation of acoustic courtship signals in insects and amphibians: no 505 evidence for bimodality, but identical dependence on duration. Ethology 115(2): 134506 140. doi:10.1111/j.1439-0310.2008.01587.x.

507 Revell, L.J. 2012. phytools: An R package for phylogenetic comparative biology (and other 508 things). Methods Ecol. Evol. 3: 217-223. doi:10.1111/j.2041-210X.2011.00169.x.

509 Röhr, D.L., Camurugi, F., Martinez, P.A., Sousa $\square$ Lima, R.S., Juncá, F.A. and Garda, A.A., In $510 \quad$ Press. Habitat $\square$ dependent advertisement call variation in the monkey frog Phyllomedusa $511 \quad$ nordestina. Ethology. doi: 10.1111/eth.13017.

512 Rosso, A., and Castellano, S. 2006. Variation in call temporal properties and female

513 preferences in Hyla intermedia. Behaviour 143(4): 405-424. 
515 Ryan, M.J. 1980. Female mate choice in a neotropical frog. Science 209(4455): 523-525. doi: 10.1126/science.209.4455.523.

517 Ryan, M.J. 1988. Energy, calling, and selection. Am. Zool. 28(3): 885-898.

518 Ryan, M.J., Cocroft, R.B., and Wilczynski, W. 1990. The role of environmental selection in 519 intraspecific divergence of mate recognition signals in the cricket frog, Acris crepitans.

$520 \quad$ Evolution 44: 1869-1872. doi:10.2307/2409514.

521 Ryan, M.J., and Kime, N.M. 2003. Selection on long-distance acoustic signals. In Acoustic 522 Communication. Edited by A.M. Simmons, A.N. Popper, and R.R. Fay. Springer, New $523 \quad$ York. pp. 225-273.

524 Smith, M.J., Roberts, J.D., Hammond, T.J., and Davis, R.A. 2003. Intraspecific variation in 525 the advertisement call of the sunset frog Spicospina flammocaerulea (Anura:

526 Myobatrachidae): A frog with a limited geographic distribution. J. Herpetol. 37(2): 285527291.

528 Snyder, W.F., and Jameson, D.L. 1965. Multivariate geographic variation of mating call in 529 populations of the Pacific tree frog (Hyla regilla). Copeia 1965(2): 129-142.

530 Sullivan, B.K. 1982. Significance of size, temperature and call attributes to sexual selection in 531 Bufo woodhousei australis. J. Herpetol. 16: 103-106.

532 Sullivan, B.K. 1989. Interpopulational variation in vocalizations of Bufo woodhousii. J.

$533 \quad$ Herpetol. 23(4): 368-373.

534 Sullivan, B.K. 1992. Sexual selection and calling behavior in the American Toad (Bufo 535 americanus). Copeia 1992(1): 1-7.

536 Wells, K.D. 1977. The social behaviour of anuran amphibians. Anim. Behav. 25(3): 666-693. doi:10.1016/0003-3472(77)90118-X.

538 Wiley, R.H., and Richards, D.G. 1978. Physical constraints on acoustic communication in the 
539 atmosphere: Implications for the evolution of animal vocalizations. Behav. Ecol.

$540 \quad$ Sociobiol. 3: 69-94.

541 Wickham, H., Averick, M., Bryan, J., Chang, W., McGowan, L., François, R., Grolemund, G.,

542 Hayes, A., Henry, L., Hester, J. and Kuhn, M., 2019. Welcome to the Tidyverse. J. of

543 Open Source Softw., 4(43): 1686.

544 Wilkins, M.R., Seddon, N., and Safran, R.J. 2013. Evolutionary divergence in acoustic

545 signals: Causes and consequences. Trends Ecol. Evol. 28(3): 156-166. Elsevier Ltd.

$546 \quad$ doi:10.1016/j.tree.2012.10.002.

547 Wollenberg, K.C., Glaw, F., Meyer, A., and Vences, M. 2007. Molecular phylogeny of

548 Malagasy reed frogs, Heterixalus, and the relative performance of bioacoustics and

549 color-patterns for resolving their systematics. Mol. Phylogenet. Evol. 45(1): 14-22.

$550 \quad$ doi:10.1016/j.ympev.2007.06.024.

551 Wright, S. 1984. Evolution and the Genetics of Populations. In 3rd edition. University of

552 Chicago press, Chicago.

553 Ziegler, L., Arim, M., and Bozinovic, F. 2016. Intraspecific scaling in frog calls: the interplay 554 of temperature, body size and metabolic condition. Oecologia 181(3): 673-681. Springer

555 Berlin Heidelberg. doi:10.1007/s00442-015-3499-8. 


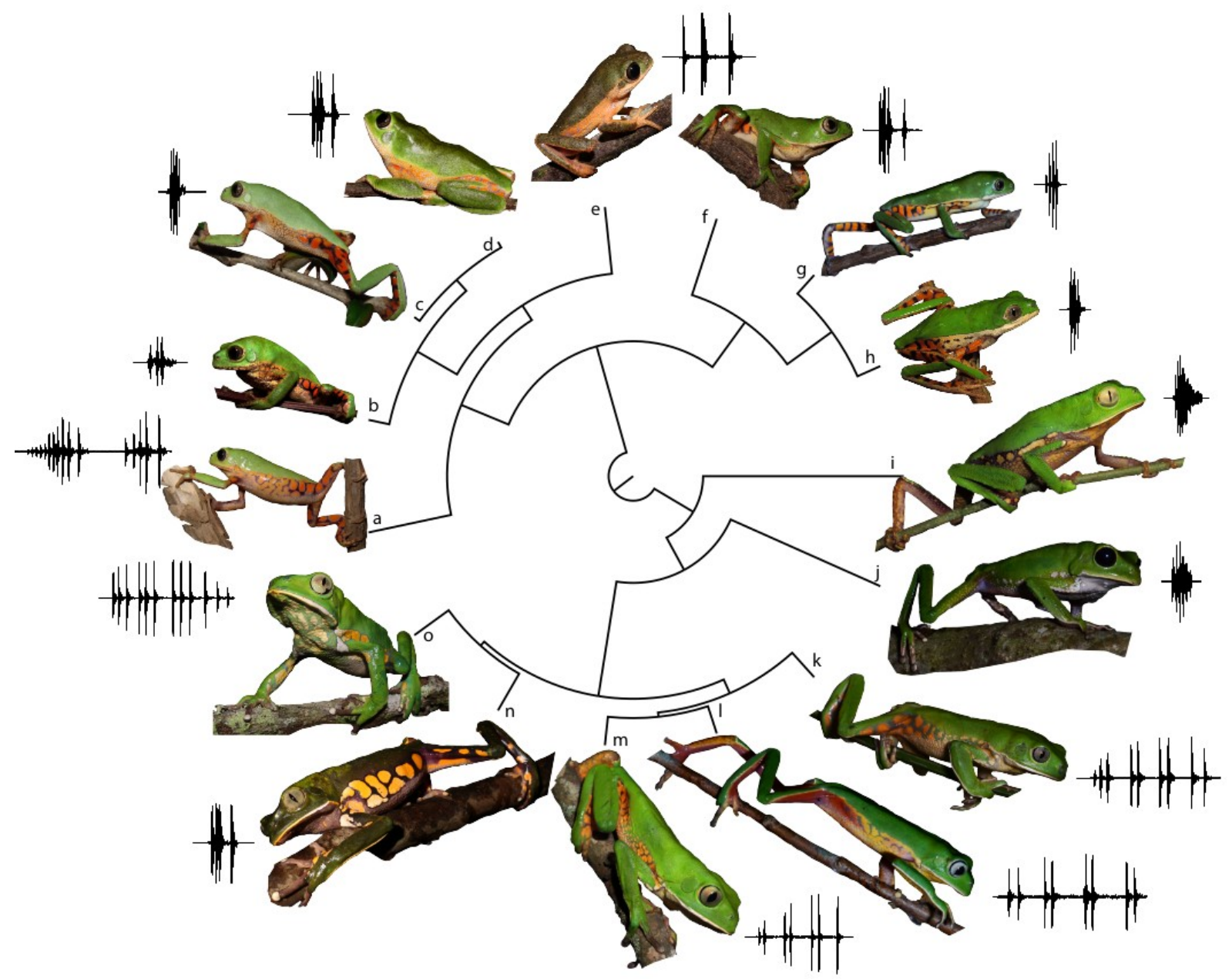

556 Figure 1. Phylogenetic tree based on Pyron and Wiens (2011) including all species of phyllomedusid recorded

557 and a representation of their advertisement call (oscillogram). Species are represented as: Pithecopus

558 megacephalus (Miranda-Ribeiro, 1926) (a), Pithecopus ayeaye Lutz, 1966 (b), Pithecopus oreades (Brandão,

559 2002) (c), Pithecopus centralis (Bokermann, 1965) (d), Pithecopus rohdei (Mertens, 1926) (e), Pithecopus

560 nordestinus (Caramaschi, 2006) (f), Pithecopus azureus (Cope, 1862) (g), Pithecopus hypocondrialis (Daudin,

561 1800) (h), Phyllomedusa vaillantii Boulenger, 1882 (i), Phyllomedusa camba De la Riva, 1999 (j),

562 Phyllomedusa iheringii Boulenger, 1885 (k), Phyllomedusa distincta Lutz, 1950 (1), Phyllomedusa tetraploidea

563 Pombal and Haddad, 1992 (m), Phyllomedusa burmeisteri Boulenger, 1882 (n), Phyllomedusa bahiana Lutz,

$5641925(0)$ 


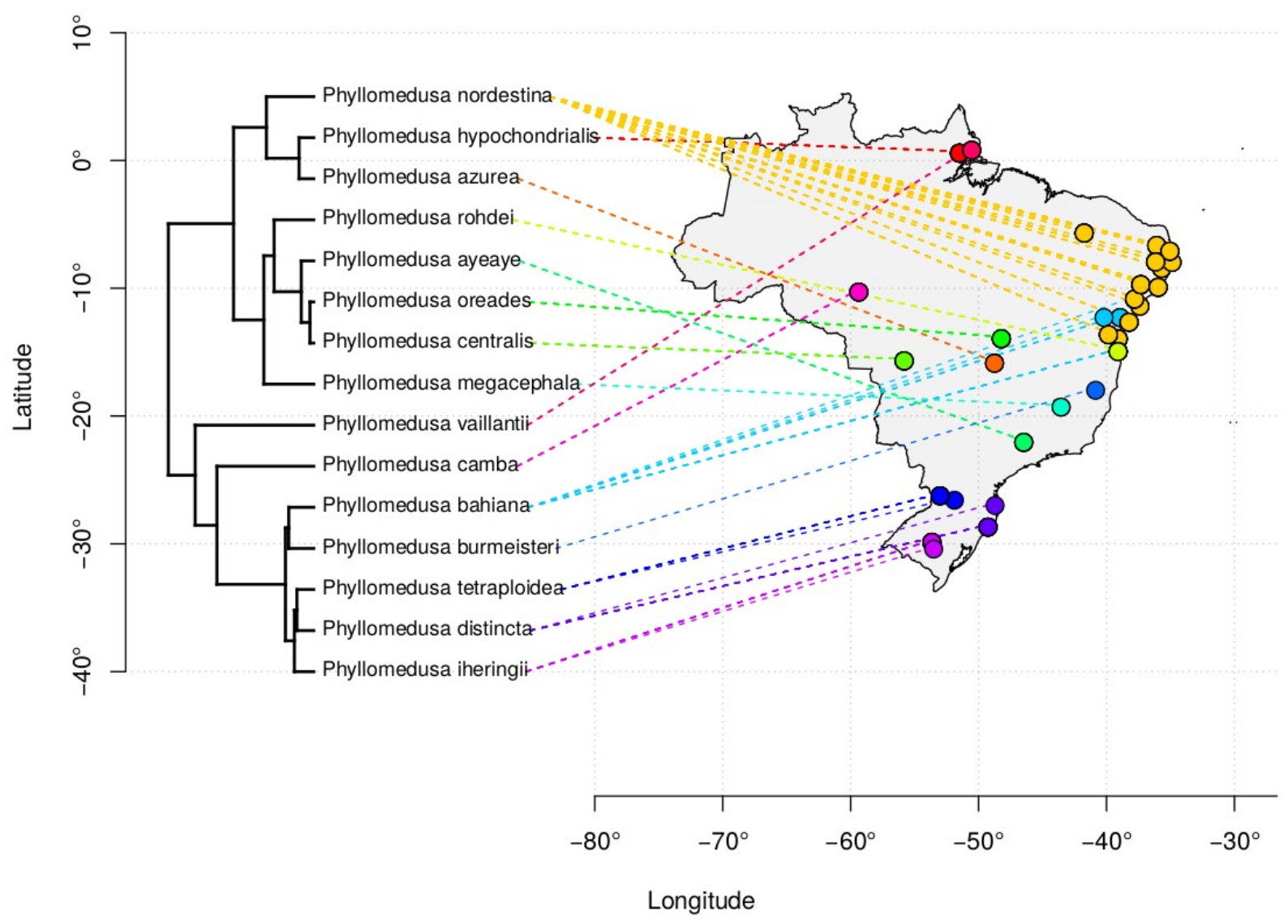

565 Figure 2. Sampling points of all populations recorded and phylogenetic relationship among 15 species of

566 monkey tree frogs (family Phyllomedusidae) used in this study, in Brazil. 


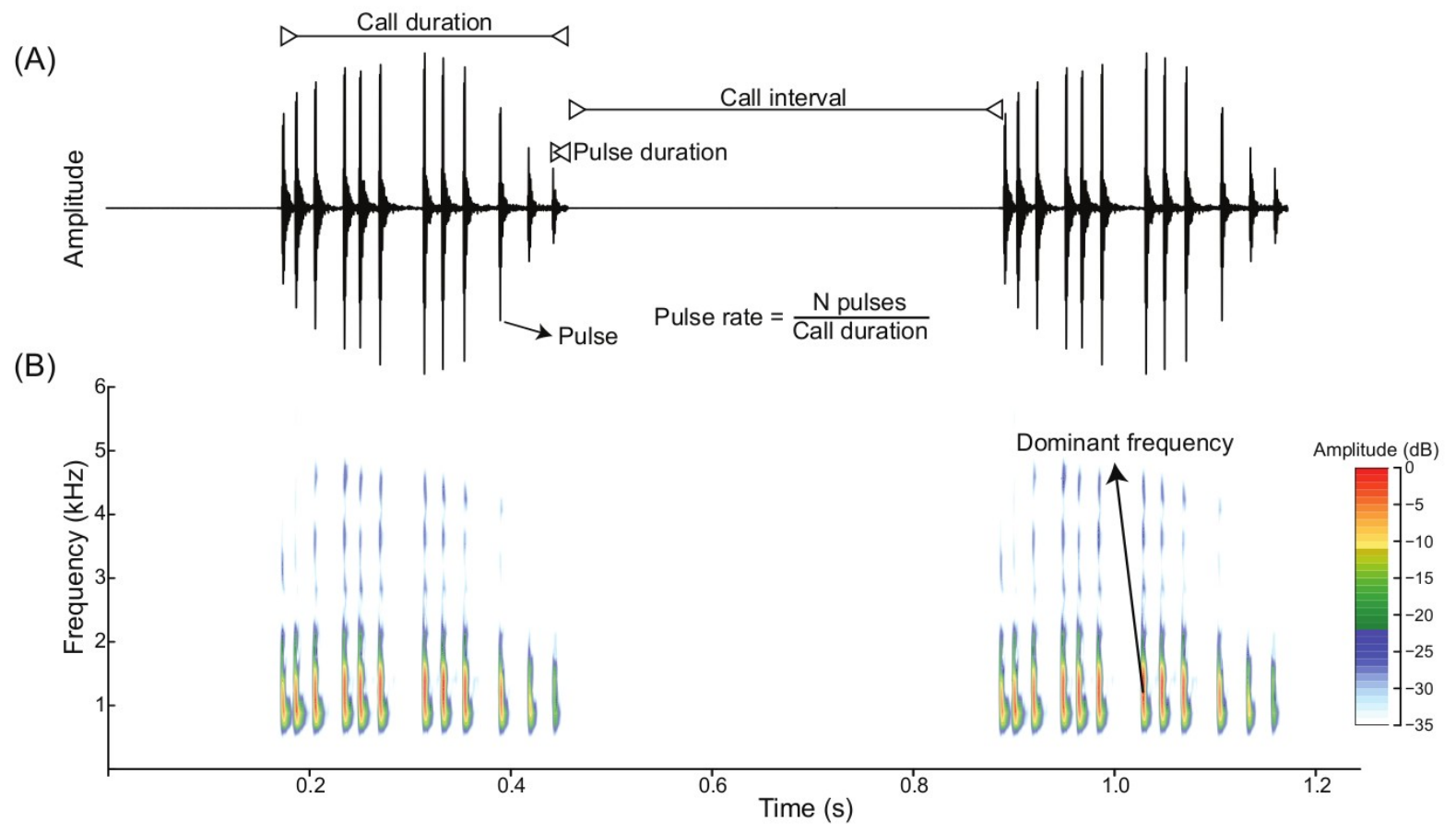

567 Figure 3. Acoustic parameters analyzed for Phyllomedusa and Pithecopus. Temporal parameters evaluated are

568 shown in the oscillogram (A) and spectral parameters in the spectrogram (B). 


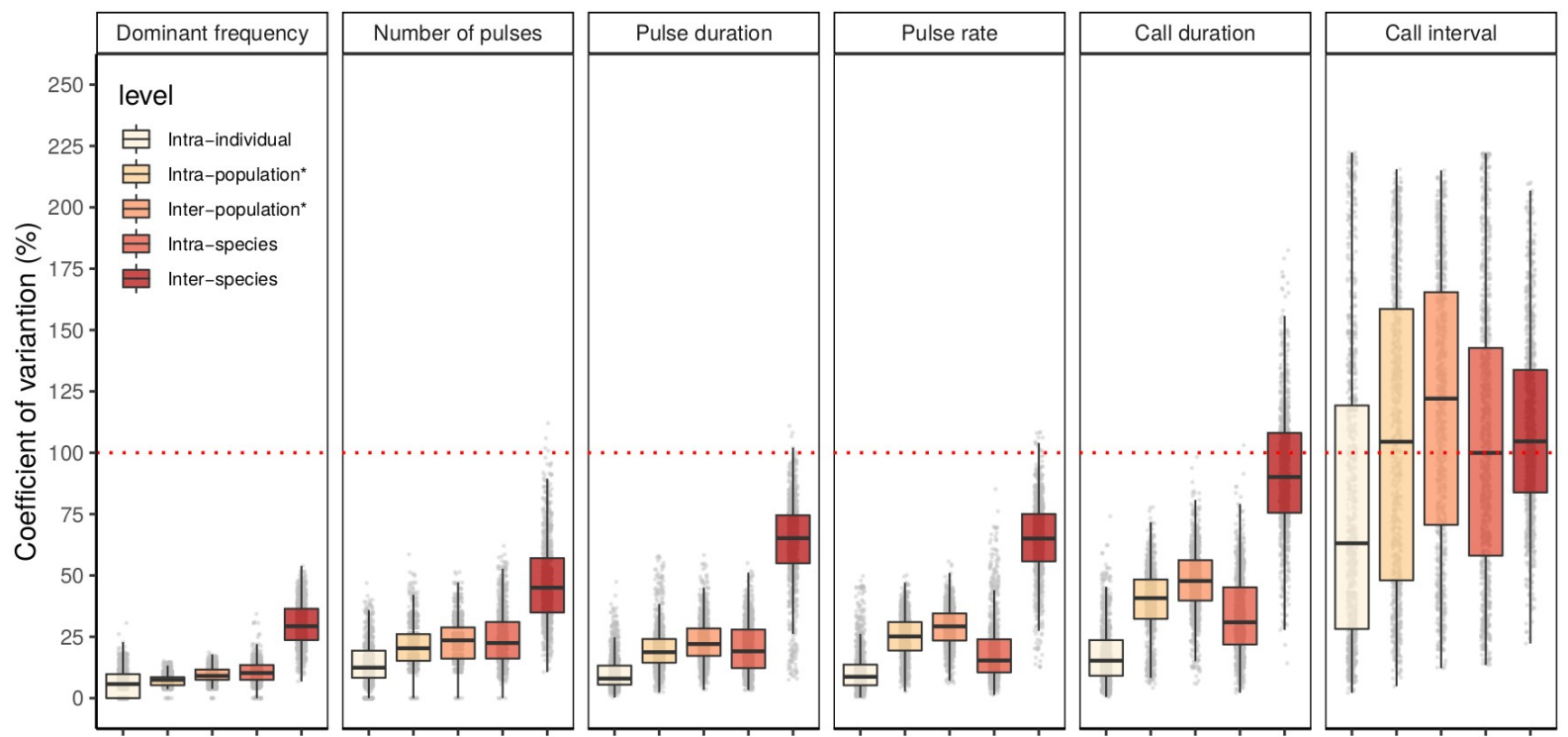

569 Figure 4. Variability of six acoustic parameters from the advertisement call of 15 species of monkey tree frogs

570 (family Phyllomedusidae) at different levels. Coefficient of variation was calculated based on a stratified

571 hierarchical subsampling method in which we repeatedly drew from our data pool five different calls. This

572 procedure was repeated 1,000 times for each parameter at each level. *Levels in which the coefficient of

573 variation was calculated only with samples from Pithecopus nordestinus. 


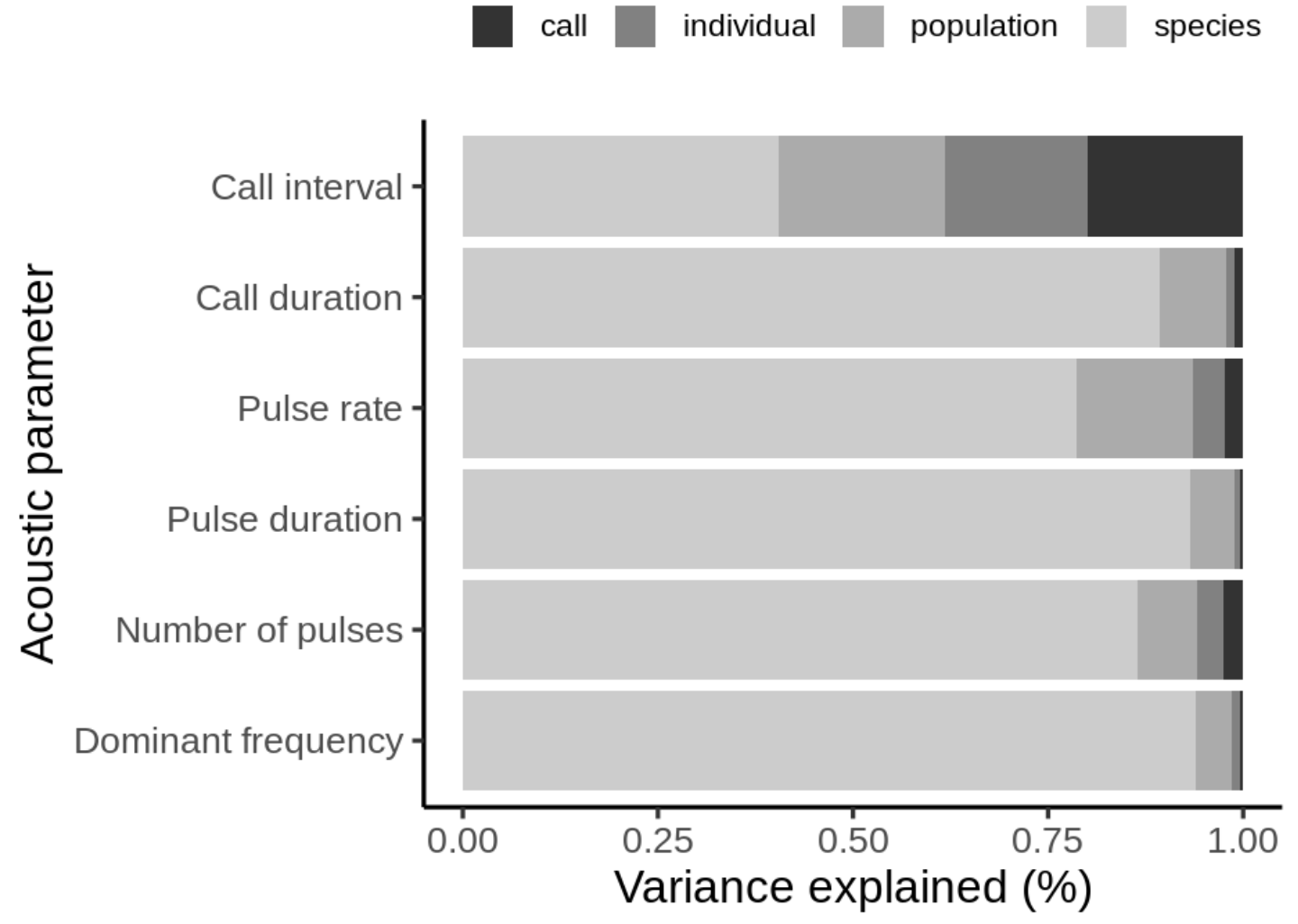

574 Figure 5. Results of the hierarchical ANOVA showing what percentage of the variability of the advertisement

575 call of 15 species of monkey tree frogs (family Phyllomedusidae) is attributed to each level for all acoustic

576 parameters: dominant frequency; number of pulses; pulse duration; pulse rate; call duration; interval between

577 calls. 
578 Table 1. Detailed step by step procedure used to draw calls from our data pool in the stratified hierarchical

579 subsampling method used to calculate the coefficient of variation of the advertisement call of phyllomedusid

580 species at different levels for each acoustic parameter.

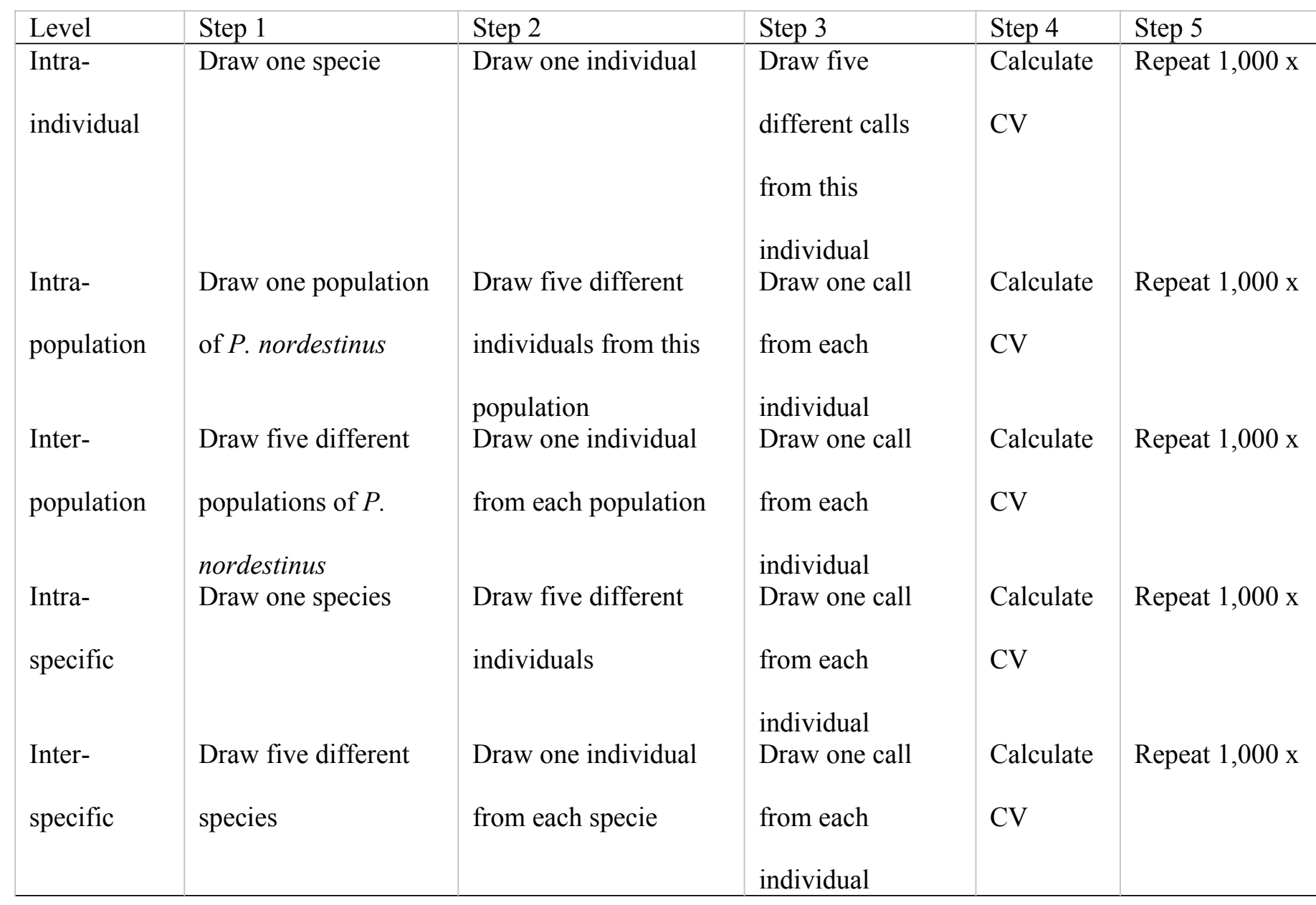


581 Table 2. Advertisement call description for all species of monkey tree frogs (family Phyllomedusidae) recorded,

582 with number of individuals and calls per species. Mean, standard deviation, maximum and minimum values for

583 each acoustic parameter, air temperature (Temp) and body size (BS). Acoustic parameters are abbreviated as:

584 call duration (CD), dominant frequency (DF), call interval (CI), number of pulses (NP), pulse rate (PR) and pulse

585 duration (PD).

\begin{tabular}{|c|c|c|c|c|c|c|c|c|c|c|}
\hline Species & $\mathbf{N}$ ind. & N of calls & CD (s) & DF (Hz) & CI (s) & NP & PR (pulse/s) & PD (s) & Temp $\left({ }^{\circ} \mathrm{C}\right)$ & BS (mm) \\
\hline Pithecopus nordestinus & 100 & 2227 & $0.04 \pm 0.02$ & $2079.1 \pm 194$ & $9.09 \pm 26.60$ & $3.81 \pm 0.91$ & $109.91 \pm 32.99$ & $0.005 \pm 0.001$ & $20.39 \pm 2.23$ & $34.36 \pm 2.43$ \\
\hline (Caramaschi, 2006) & & & $(0.01-0.09)$ & $(1500-2625)$ & $(0.02-290.30)$ & $(2-8)$ & $(40-230.77)$ & $(0.0005-0.01)$ & $(16-25.4)$ & $(29.57-40.31)$ \\
\hline Pithecopus azureus (Cope, & 4 & 45 & $0.03 \pm 0.00$ & $2291.2 \pm 59$ & $21.60 \pm 20.66$ & $4 \pm 0$ & $135.71 \pm 7.61$ & $0.005 \pm 0.001$ & $22.5 \pm 1.71$ & $34.09 \pm 1.56$ \\
\hline 1862) & & & $(0.03-0.03)$ & $(2153-2412)$ & $(1.43-88.38)$ & $(4-4)$ & $(111.11-150)$ & $(0.004-0.006)$ & $(20-23.9)$ & $(31.79-35.27)$ \\
\hline Pithecopus ayeaye Lutz, 1966 & 5 & 96 & $0.09 \pm 0.04$ & $1471.4 \pm 168$ & $7.3 \pm 12.85$ & $5.63 \pm 1.14$ & $71.52 \pm 40.51$ & $0.008 \pm 0.002$ & 17.6 & $40.49 \pm 1.43$ \\
\hline & & & $(0.03-0.16)$ & $(1206-1723)$ & $(0.25-60.04)$ & $(3-10)$ & $(30.30-208.33)$ & $(0.003-0.015)$ & & $(37.97-41.43)$ \\
\hline Pithecopus megacephalus & 2 & 20 & $0.32 \pm 0.09$ & $1809.4 \pm 140$ & $42.74 \pm 34.67$ & $13.4 \pm 3.59$ & $39.78 \pm 7.99$ & $0.005 \pm 0.001$ & 23 & $38.49 \pm 0.11$ \\
\hline (Miranda-Ribeiro, 1926) & & & $(0.25-0.57)$ & $(1688-2063)$ & $(7.03-137.45)$ & $(8-22)$ & $(23.38-54.14)$ & $(0.004-0.006)$ & & $(38.56-38.41)$ \\
\hline Pithecopus centralis & 9 & 215 & $0.04 \pm 0.01$ & $1271.5 \pm 175$ & $7.55 \pm 12.43$ & $4.42 \pm 0.84$ & $115.82 \pm 28.47$ & $0.004 \pm 0.001$ & NA & NA \\
\hline (Bokermann, 1965) & & & $(0.02-0.1)$ & $(938-1550)$ & $(0.2-79.32)$ & $(3-7)$ & $(45.98-166.67)$ & $(0.002-0.008)$ & & \\
\hline Pithecopus oreades (Brandão, & 7 & 200 & $0.03 \pm 0.01$ & $1679.6 \pm 153$ & $15.36 \pm 42.19$ & $3.93 \pm 0.64$ & $1140.52 \pm 23.25$ & $0.004 \pm 0.001$ & NA & NA \\
\hline 2002) & & & $(0.02-0.07)$ & $(1125-2067)$ & $(0.19-352.91)$ & $(3-7)$ & $(79.37-285.71)$ & $(0.002-0.007)$ & & \\
\hline Pithecopus hypocondrialis & 11 & 354 & $0.03 \pm 0.01$ & $1970.3 \pm 98$ & $8.16 \pm 19.46$ & $4.07 \pm 0.75$ & $141.15 \pm 14.44$ & $0.005 \pm 0.001$ & $22.66 \pm 0.53$ & $35.85 \pm 1.62$ \\
\hline (Daudin, 1800) & & & $(0.02-0.05)$ & $(1688-2250)$ & $(0.20-195.22)$ & $(3-7)$ & $(103.45-200)$ & $(0.003-0.008)$ & $(22.2-23.5)$ & $(32.67-37.6)$ \\
\hline Pithecopus rohdei (Mertens, & 7 & 47 & $0.15 \pm 0.07$ & $2014.6 \pm 189$ & $37.13 \pm 43.13$ & $5.23 \pm 2.40$ & $33.16 \pm 4.56$ & $0.018 \pm 0.003$ & $23.51 \pm 0.23$ & $44.15 \pm 2.03$ \\
\hline 1926) & & & $(0.08-0.42)$ & $(1688-2250)$ & $(2.77-183.16)$ & $(3-11)$ & $(25.16-46.39)$ & $(0.011-0.024)$ & $(23.2-23.8)$ & $(41.63-46.36)$ \\
\hline Phyllomedusa bahiana Lutz, & 10 & 115 & $0.31 \pm 0.17$ & $1141.3 \pm 148$ & $18.41 \pm 14.26$ & $14.50 \pm 4.17$ & $43.09 \pm 9.25$ & $0.014 \pm 0.004$ & $21.43 \pm 2.9$ & $75.32 \pm 2.99$ \\
\hline 1925 & & & $(0.13-0.99)$ & $(938-1313)$ & $(0.99-74.14)$ & $(7-26)$ & $(20.62-63.49)$ & $(0.006-0.021)$ & $(15.3-24.2)$ & $(69.31-78.48)$ \\
\hline Phyllomedusa burmeisteri & 1 & 5 & $0.12 \pm 0.01$ & $1102.5 \pm 154$ & $8.40 \pm 4.86$ & $6.8 \pm 0.45$ & $51.45 \pm 0.78$ & $0.004 \pm 0.000$ & 25.7 & 63 \\
\hline Boulenger, 1882 & & & $(0.1-0.13)$ & $(1034-1378)$ & $(3.72-15.22)$ & $(6-7)$ & $(50.42-52.17)$ & $(0.004-0.004)$ & & \\
\hline Phyllomedusa camba De la & 5 & 260 & $0.04 \pm 0.01$ & $669 \pm 105$ & $5.81 \pm 15.20$ & $4.71 \pm 1.12$ & $112.59 \pm 8.56$ & $0.005 \pm 0.001$ & $22.9 \pm 1.09$ & $83.03 \pm 2.25$ \\
\hline Riva, 1999 & & & $(0.02-0.07)$ & $(5623-1125)$ & $(0.09-121.42)$ & $(3-9)$ & $(88.88-142.86)$ & $(0.003-0.006)$ & $(22.1-24.1)$ & $(79.49-85.34)$ \\
\hline Phyllomedusa distincta Lutz, & 9 & 113 & $0.23 \pm 0.05$ & $1299.2 \pm 99$ & $22.98 \pm 12.38$ & $6.83 \pm 1.06$ & $27.88 \pm 3.64$ & $0.017 \pm 0.001$ & $18.57 \pm 1.14$ & $50.51 \pm 2.52$ \\
\hline 1950 & & & $(0.13-0.35)$ & $(1125-1875)$ & $(9.2-82.56)$ & $(5-10)$ & $(15.24-35.71)$ & $(0.013-0.024)$ & $(16-19.8)$ & $(47.46-53.98)$ \\
\hline Phyllomedusa iheringii & 7 & 164 & $0.32 \pm 0.07$ & $1240.5 \pm 132$ & $17.35 \pm 12.20$ & $9.31 \pm 1.80$ & $27.74 \pm 3.04$ & $0.017 \pm 0.003$ & $15.59 \pm 0.74$ & $54.26 \pm 2.91$ \\
\hline Boulenger, 1885 & & & $(0.19-0.49)$ & $(938-1500)$ & $(1.01-109.48)$ & $(6-14)$ & $(20.75-36.36)$ & $(0.012-0.025)$ & $(14.9-16.7)$ & $(49.69-58.13)$ \\
\hline Phyllomedusa tetraploidea & 7 & 121 & $0.03 \pm 0.09$ & $1182.3 \pm 108$ & $18.04 \pm 13.75$ & $9.28 \pm 2$ & $29.39 \pm 3.81$ & $0.015 \pm 0.001$ & $18.97 \pm 1.56$ & $58.91 \pm 4.39$ \\
\hline Pombal and Haddad, 1992 & & & $(0.19-0.65)$ & $(938-1313)$ & $(2.24-77.32)$ & $(5-15)$ & $(20.634-38.095)$ & $(0.010-0.022)$ & $(16-20.6)$ & $(54.52-65.48)$ \\
\hline Phyllomedusa vaillantii & 4 & 12 & $0.04 \pm 0.01$ & $1609.4 \pm 149$ & $64.12 \pm 65.69$ & $7.92 \pm 1.31$ & $178.12 \pm 15.68$ & $0.004 \pm 0.001$ & $23.05 \pm 1.37$ & $49.76 \pm 2.1$ \\
\hline Boulenger, 1882 & & & $(0.03-0.053)$ & $(1313-1875)$ & $(11.99-180.15)$ & $(5-10)$ & $(155.56-212.12)$ & $(0.002-0.005)$ & $(22-25)$ & $(47.08-51.9)$ \\
\hline
\end{tabular}


586 Table 3. Influence of body size and environmental temperature on the acoustic parameters of the advertisement

587 call of 15 species of monkey tree frogs (family Phyllomedusidae). Linear mixed models included the mean value

588 of the acoustic parameter for each individual and the species was included as a random effect. Acoustic

589 parameters are abbreviated as: call duration (CD), dominant frequency (DF), call interval (CI), pulse duration

590 (PD), number of pulses (NP) and pulse rate (PR). In bold $P$-values $\leq 0.05$.

\begin{tabular}{cccccc|ccccc}
\hline & \multicolumn{4}{c}{ Body size } & \multicolumn{5}{c}{ Temperature } \\
\cline { 2 - 12 } & Estimate & Chisq & $P$-value & $r^{2}$ conditional $r^{2}$ marginal & Estimate & Chisq & $P$-value & $r^{2}$ conditional $r^{2}$ margina \\
\hline DF & -23.885 & 64.313 & $<\mathbf{0 . 0 0 1}$ & 0.878 & 0.643 & 9.474 & 2.638 & 0.104 & 0.908 & 0.002 \\
CD & 0.001 & 1.285 & 0.257 & 0.860 & 0.024 & -0.008 & 21.518 & $<\mathbf{0 . 0 0 1}$ & 0.871 & 0.028 \\
CI & -0.074 & 0.074 & 0.790 & 0.300 & 0.002 & 0.412 & 0.305 & 0.581 & 0.277 & 0.002 \\
PD & $<0.001$ & 0.151 & 0.697 & 0.915 & 0.002 & $<0.00001$ & 0.035 & 0.851 & 0.917 & $<0.001$ \\
NP & 0.049 & 1.808 & 0.179 & 0.827 & 0.038 & -0.164 & 9.186 & $\mathbf{0 . 0 0 2}$ & 0.848 & 0.014 \\
PR & -1.296 & 5.041 & $\mathbf{0 . 0 2 5}$ & 0.855 & 0.095 & 2.869 & 11.075 & $\mathbf{0 . 0 0 1}$ & 0.836 & 0.018 \\
\hline
\end{tabular}


591 Table 4. Results of Mantel test evaluating which acoustic parameters of the advertisement call of Pithecopus

592 nordestinus (Caramaschi, 2006) are correlated to the geographic distance between populations. In bold $P$-values

$593 \leq 0.05$.

\begin{tabular}{lcccc}
\hline & \multicolumn{2}{c}{ Individuals } & \multicolumn{2}{c}{ Populations } \\
\cline { 2 - 5 } Source & $\boldsymbol{r}$ & $P-$ & $\boldsymbol{r}$ & $P-$ \\
& & & & \\
& & value & & value \\
\hline $\begin{array}{l}\text { Call Duration } \\
\text { Dominant }\end{array}$ & 0.064 & 0.053 & 0.096 & 0.175 \\
& & & & \\
Frequency & 0.035 & 0.190 & 0.068 & 0.307 \\
Number of Pulses & 0.018 & 0.316 & 0.130 & 0.116 \\
& - & & & \\
& & & & \\
Pulse Duration & 0.017 & 0.601 & 0.064 & 0.282 \\
Pulse Rate & 0.109 & $\mathbf{0 . 0 0 4}$ & 0.137 & 0.135 \\
& - & & & \\
$\quad$ & & & & \\
Call Interval & 0.004 & 0.459 & 0.058 & 0.248 \\
\hline
\end{tabular}


594 Table 5. Phylogenetic signal for acoustic parameters and body size of monkey tree frogs Phyllomedusa and

595 Pithecopus calculated through K statistic (Blomberg et al., 2003). PIC.mean is the mean observed PIC

596 (phylogenetic independent contrasts) variance and PIC.rdn.mean is the mean random PIC variance.

\begin{tabular}{lcccc}
\hline \multicolumn{1}{c}{ Source } & K statistic & PIC.mea & PIC.rdn.mean & $\boldsymbol{P}$ - \\
& \multicolumn{4}{c}{ n } \\
& \multicolumn{4}{c}{ value } \\
\hline Call Duration & 0.74 & 0.001 & 0.004 & 0.010 \\
Dominant & 0.64 & 16689.36 & 56643.05 & 0.005 \\
& & & & \\
Frequency & & & & \\
Call Interval & 0.69 & 23.48 & 72.39 & 0.013 \\
Number of Pulses & 0.54 & 0.96 & 2.68 & 0.017 \\
Pulse Rate & 0.79 & 198.23 & 714.60 & 0.006 \\
Pulse Duration & 0.57 & $3.29 \mathrm{E}-06$ & $9.18 \mathrm{E}-06$ & 0.031 \\
Body Size & 1.16 & 11.44 & 40.84 & 0.003 \\
\hline
\end{tabular}

